\title{
PERFIL SENSORIAL E COMPOSIÇÃO FÍSICO-QUIMICA DE CERVEJAS PROVENIENTES DE DOIS SEGMENTOS DO MERCADO BRASILEIRO ${ }^{1}$
}

\author{
F.B. ARAÚJO2 ${ }^{2}$, P.H.A. SILVA ${ }^{3, *}$, V.P.R. MINIM ${ }^{4}$
}

\begin{abstract}
RESUMO
Foram estudadas seis marcas de cervejas produzidas no Brasil, das quais as marcas 1, 2, 3 e 4 foram provenientes de microcervejarias e as 5 e 6 são líderes do mercado nacional, com o objetivo de avaliar sua qualidade pelas características fisico-químicas e sensoriais. A marca 1 constituiu cerveja "ale", tipo Trigo; a 2, cerveja "lager", tipo Amber; e as demais foram cervejas "lager", tipo Pilsen. As marcas 1 e 2 apresentaram concentrações mais elevadas de ácidos voláteis e foram as que evidenciaram maior intensidade do gosto amargo. Observou-se que as marcas provenientes de microcervejarias foram as que apresentaram maior intensidade dos atributos sensoriais, devendo-se ressaltar que as marcas 1 e 2 foram as que apresentaram cor, aroma de levedura, aroma de fruta, aroma de papelão, sabor oxidado, gosto doce e aroma de diacetil mais intensos. As marcas que apresentaram, mediante análise físico-química, maior concentração de acetato de etila foram as que tiveram aroma de fruta perceptivel pela equipe sensorial, não sendo este atributo detectado nas marcas 3, 4, 5 e 6. O aroma de solvente não foi detectado em nenhuma das marcas avaliadas, o que indica que a concentração de álcoois superiores estava abaixo do limiar sensorial de detecção. As marcas 3, 4 e 5 foram utilizadas para avaliar a aceitação do produto, não tendo sido verificada diferença significativa $(\mathrm{p} \geq 0,05)$ entre elas, que se situaram entre os termos hedônicos "gostei muito" e "gostei ligeiramente", o que contraria o esperado, já que as microcervejarias objetivam uma cerveja diferenciada e de maior atração para o consumidor.

Palavras-chave: cerveja; microcervejaria; aceitação; qualidade.
\end{abstract}

\section{SUMMARY}

SENSORIAL AND PHYSICAL-CHEMICAL EVALUATION OF BEERS DERIVING FROM TWO SEGMENTS OF BRAZILIAN MARKET. Six brands of beer produced in Brazil, of which brands 1,2, 3 and 4 derived from small brewery and brands 5 and 6 were leaders of the national market, were studied to evaluate their quality through physical-chemical and sensorial characteristics. Brand 1 constitutes the "ale" Wheat type and brand 2 the "lager" Amber type. The other brands were "lager" Pilsen type. Brands 1 and 2 presented high volatile acidity, and were also identified by the Quantitative Descriptive Analysis as presenting the greatest intensity of bitter flavor. It was observed that the brands deriving from small brewery presented larger intensity of sensorial attributes, so that brands 1 and 2 presented color, yeast aroma, fruit aroma, cardboard aroma, oxidized flavor, sweet taste and more intense diacetyl aroma. The brands that presented, through the chemico-physical analysis, higher concentration of ethyl acetate were the ones that had fruit aroma perceptible by the sensorial team, not being this attribute detected in brands 3, 4, 5 and 6 . Solvent aroma was not detected in any of the appraised brands, suggesting that the concentration higher alcohols is below the sensorial threshold of detection. Brands 3,4 and 5 were used to evaluate the acceptance of the product, with no significant difference $(\mathrm{p} \geq 0.05)$ among the brands, which were ranked among the hedonic terms "I liked it very much" and "I liked it slightly", which contradicts the expected, since small breweries aim a differentiated beer with greater attraction for the consumer.

Keywords: microbrewery; beer; sensory evaluation.

\section{1 - INTRODUÇÃO}

O mercado de cervejas no Brasil sempre se caracterizou pela presença de poucas marcas de cerveja, predominantemente do tipo Pilsen, que é uma bebida com características de sabor suave, $\mathrm{pH}$ em torno de 4,3, clara e limpida. Ao nivel nacional, a produção deste tipo de cerveja se concentra em grandes fábricas, que representam as principais marcas distribuídas em todo o território nacional.

Embora incipiente, a produção de cerveja em microescala já se manifesta no Brasil, acompanhando a tendência já existente em outros países. A cerveja de microcervejaria caracteriza-se por ser um produto mais

\footnotetext{
Recebido para publicação em 02/05/2001. Aceito para publicação em 03/10/2002 (000632)

2. Universidade Federal de Viçosa, CEP 36571-000 - Viçosa-MG

3. Universidade Federal de Viçosa, Departamento de Tecnologia de Alimentos, CEP36571-000 - Viçosa-MG, E-mail: phasilva@mail.ufv.br, Tel. 31-3899-1851, Fax: 31-3899-2208.

4. Universidade Federal de Viçosa, Departamento de Tecnologia de Alimentos, CEP 36571-000 - Viçosa-MG.

* A quem a correspondência deve ser enviada.
}

encorpado e de aroma e sabor mais pronunciados, sendo consumida principalmente por pessoas mais exigentes em termos de qualidade sensorial, que buscam um produto diferenciado, independente do preço. Um microcervejeiro geralmente adota como alternativa tecnológica uma escala de produção de até 50.000 litros por ano, ou seja, uma produção mensal média de 4.160 litros. Nos Estados Unidos entende-se como microcervejaria todas as empresas que produzem até 15 mil barris por ano, onde um barril equivale a 3,78 litros [12].

As microcervejarias são altamente dependentes da disponibilidade de leveduras, malte, lúpulo e outros ingredientes, e os investimentos nas instalações e nos equipamentos são limitados. Devido à necessidade de treinamentos muitas vezes prolongados e ao elevado custo, muitas microcervejarias brasileiras não possuem suporte próprio para pesquisa, não podendo, desta forma, testar e caracterizar seus novos produtos [14, 15].

Cervejas são classificadas em de alta ("ale") e de baixa ("lager") fermentação, sendo os sabores e aromas das cervejas "lager" mais suaves e leves. Cervejas do tipo "lager" são fermentadas à temperatura de 3,3 a $13^{\circ} \mathrm{C}$ e a duração da fermentação e da maturação pode ser de 4 a 
12 semanas. Devido as baixas temperaturas usadas no processo, os sabores e aromas das cervejas "lager" são mais suaves e leves em comparação com as "ales" [1, 9]. As cervejas do tipo "lager", que são elaboradas com cepas de Saccharomyces calsbergensis, são mais populares mundialmente e as do tipo "ale", elaboradas com cepas de Saccharomyces cerevisae, são muito populares na Grã Bretanha [18]. Embora nitidamente diferenciadas em tecnologia cervejeira, as classificações taxonômicas destas leveduras tendem a agrupá-las em apenas uma espécie, Saccharomyces cerevisae [7]. Como exemplos de cerveja tipo "lager" pode-se citar a Bock, Dortmunder, Munchner, Pilsener e Vienna (Marzen) e de cerveja tipo "ale" tem-se a Porter, Stout, Salsons, Alt, Light ale, Pale ale, Bitters e Barley wines [17].

A cerveja é uma das bebidas mais delicadas e lábeis, possuindo um complexo, mas moderado, aroma e sabor. O equilíbrio de seus compostos voláteis e não-voláteis é responsável pela aceitação e qualidade da bebida. A composição em ésteres, aldeídos, dicetonas vicinais, ácidos orgânicos, álcoois superiores, fenóis, iso- $\alpha$-ácidos e outros compostos está diretamente relacionada com a qualidade. A perda de qualidade por sabores indesejáveis é um sério problema nas indústrias cervejeiras.

Como a qualidade é um instrumento fundamental para se obter vantagens no mercado, pois é ela que influencia o comportamento do consumidor, é necessário ter informações acerca do produto, de modo que este possa satisfazer as necessidades do consumidor.

A análise descritiva quantitativa descreve as propriedades sensoriais do produto e mede a intensidade em que essas propriedades são percebidas pelos provadores, o que permite uma descrição das características sensoriais com precisão em termos matemáticos. Estes atributos podem ser correlacionados com diferentes tipos de substâncias voláteis e não voláteis presentes na amostra.

O presente trabalho teve como objetivos comparar os perfis sensoriais de cervejas produzidas em microcervejarias com os das grandes marcas produzidas em nivel nacional e relacionar os atributos sensoriais com os resultados obtidos por análise físico-química.

\section{2 - MATERIAL E MÉTODOS}

\section{1 - Materiais experimentais utilizados}

Foram analisadas amostras de cervejas de seis marcas disponiveis no mercado brasileiro, das quais quatro foram produzidas em microcervejarias e duas marcas representam o segmento líder de mercado.

\section{2 - Caracterização das marcas das cervejas utilizadas}

As marcas 1, 2, 3 e 4 foram provenientes de microcervejarias, sendo que as marcas 2, 3 e 4 foram cervejas de baixa fermentação ("lager"), as marcas 3 e 4 do tipo Pilsen e a 2 do tipo Amber. A marca 1 foi uma cerveja de alta fermentação ("ale”), tipo Trigo. As marcas 5 e 6 representaram duas grandes marcas, lideres de mercado, sendo cervejas de baixa fermentação, tipo Pilsen.
De acordo com TIPOS DE CERVEJAS [17], as cervejas tipo Trigo são processadas com malte de trigo e são freqüentemente produzidas sem passar pelo processo de filtragem. Essas cervejas podem ter sabores de fruta e/ou especiarias, podendo variar de suave à leve. Sua cor pode variar de palha à cor escura. As cervejas tipo Amber possuem um alto teor de malte caramelizado, e os sabores provenientes de lúpulo podem variar de muito suave a muito forte.

As condições de produção das cervejas do segmento de microcervejarias utilizadas neste trabalho foram levantadas por meio de questionário enviado às indústrias. De acordo com as respostas obtidas das microcervejarias, observou-se que a cerveja de marca 3 é do tipo Pilsen, sendo a cevada e o lúpulo utilizados no processamento, importados, e o lúpulo é utilizado na forma de "pellet". A levedura utilizada é Saccharomyces uvarum boirink, recebida de terceiros, pronta para inoculação. O volume de inoculação é de $15 \mathrm{~L}$ de levedura/1.600L de mosto. A água utilizada é obtida pelo sistema convencional de captação, em rede municipal, e é tratada por meio de carvão ativo e filtração física. A tina de mosturação e o tanque de fermentação e maturação são de aço inoxidável. Esta cerveja é processada como se segue: o mosto é cozido por 10 horas (aproximadamente), fermentado durante sete dias a $12^{\circ} \mathrm{C}$, e maturado em 21 dias. A cerveja é transferida para o tanque de pressão e envasada. As tinas de mosturação e o tanque de fermentação possuem capacidade de $1.600 \mathrm{~L}$. O produto é envasado em barris tipo "keg" ou vendido no próprio local, em tulipas.

O malte utilizado no processamento das marcas 1, 2 e 4, também representantes do segmento das microcervejarias, é parte nacional e parte importado, com cevada de duas ou quatro fileiras. O lúpulo é importado e é utilizado na forma de "pellet". A levedura é recebida de terceiros, pronta para inoculação, e é fornecida liofilizada. A água é adquirida pelo sistema convencional de captação, em rede municipal, e é aquecida a $168^{\circ} \mathrm{F}$ antes de ser utilizada no processamento. A tina de mosturação e o tanque de fermentação e maturação são de aço inoxidável, devendo-se ressaltar que o tanque de maturação possui cobre na parte externa. O produto é envasado em barris.

\section{3 - Métodos}

\subsection{1 - Análises físico-químicas}

As análises físico-químicas das cervejas foram realizadas, tendo sido determinados a acidez volátil, os ésteres e os álcoois superiores, segundo a metodologia de oficial adotada pelo Ministério da Agricultura [4].

Para a realização das análises, as amostras foram destiladas por arraste a vapor, para separar o álcool e outros componentes voláteis de outros componentes não-voláteis, como pigmentos, minerais, proteínas e açúcares.

O experimento foi constituido de seis tratamentos, representados pelas marcas, em delineamento inteiramente casualizado, com três repetições. Os resultados foram 
interpretados por meio da análise de variância (ANOVA), utilizando-se procedimentos do programa SAS ("Statystical Analysis System"), versão 6.12. O teste de Duncan, a 5\%, foi aplicado para comparar as médias de acidez volátil, ésteres e álcoois superiores entre as marcas.

\section{- Acidez volátil}

As determinações de acidez volátil foram realizadas de acordo com a metodologia oficial de BRASIL [4], e os resultados expressos em $\mathrm{mg} / \mathrm{L}$ de ácido acético.

\section{- Ésteres}

As determinações de ésteres foram realizadas conforme a metodologia oficial de BRASIL [4], utilizando-se um condensador de refluxo. Os resultados foram expressos em mg/L de acetato de etila.

\section{- Álcoois superiores totais}

As determinações de álcoois superiores totais foram realizadas de acordo com a metodologia oficial de BRASIL [4], utilizando-se reação colorimétrica com dimetilaminobenzaldeído, avaliando-se a intensidade do complexo a $\lambda=540 \mathrm{~nm}$. Os resultados foram expressos em $\mathrm{mg} / \mathrm{L}$ de álcoois superiores.

\section{- Teor alcoólico}

O teor alcoólico das amostras foi determinado por meio de alcoômetro previamente calibrado, pelo princípio de areometria, à temperatura de referência $\left(15^{\circ} \mathrm{C}\right)$, sendo o resultado expresso em ${ }^{\circ} \mathrm{GL}$.

\section{4 - Análise sensorial}

\subsection{1 - Análise descritiva quantitativa}

\section{- Condições do teste}

As avaliações sensoriais foram realizadas em laboratório de análise sensorial do Departamento de Tecnologia de Alimentos da Universidade Federal de Viçosa, em cabines individuais, utilizando-se iluminação vermelha para todos os atributos, exceto para aparência, que foi avaliada fora da cabine, com luz natural.

As amostras de cerveja foram servidas em copos descartáveis de $50 \mathrm{~mL}$, em bandejas plásticas, à temperatura de $10^{\circ} \mathrm{C}$, codificados com números aleatórios de três digitos, juntamente com um copo de água, para enxaguar a boca entre as avaliações.

- Recrutamento e pré-seleção dos candidatos a provadores

Voluntários para compor a equipe sensorial foram recrutados entre estudantes e funcionários da Universidade Federal de Viçosa. O recrutamento foi realizado por meio de questionário, com o objetivo de obter informações a respeito das condições de saúde, da habilidade para quantificar usando escalas de intensidade, da disponibilidade de tempo, da familiaridade com termos descritivos e do interesse em participar do teste.
A habilidade discriminatória dos candidatos foi testada por meio do método triangular (teste discriminatório), em que foram utilizadas amostras de duas marcas comerciais de cerveja. Foram realizadas seis sessões, e em cada sessão foram apresentadas e avaliadas três amostras, sendo uma diferente e duas iguais, nas quais os provadores foram solicitados a identificar a amostra diferente.

\section{- Levantamento dos termos descritivos}

Nesta etapa foi utilizado o método de lista prévia, que foi extraida e adaptada de PALAMAND [13], com os atributos próprios do produto (Figura 1).

Nome:

\begin{tabular}{l} 
Data $-\frac{1}{\text { Código da amostra: }}+\ldots$ \\
\hline
\end{tabular}

Por favor, analise cada amostra apresentada e assinale, se críticos ou não críticos, com um $(\mathrm{X})$ os atributos listados. Enxágüe a boca após a avaliação de cada amostra. Qualquer atributo percebido, diferente daqueles listados abaixo, deve ser citado no espaço nomeado como atributos sugeridos.

\section{ATRIBUTO}

\section{CRÍTICO NÃO-CRÍTICO}

Aroma de Levedura

Aroma de Papelão

Aroma de Diacetil

Aroma de Fruta

Aroma de Solvente

Aroma Alcoólico

Aroma Medicinal

Sabor Oxidado

Gosto Doce

Gosto Ácido

Gosto Amargo

Carbonatação

Atributos sugeridos ou comentários:

FIGURA 1. Lista utilizada para levantamento prévio dos atributos sensoriais da cerveja.

Foram apresentadas, em cabines individuais, seis amostras de cerveja, tendo o julgador sido orientado a considerar como crítico o atributo presente e como nãocritico o atributo ausente, de acordo com sua percepção. Foram aceitas sugestões dos provadores de possiveis atributos que não estivessem na lista. A ficha de resposta definitiva foi estabelecida com os termos que foram considerados como críticos por, pelo menos, $50 \%$ dos provadores na cabine e depois aprovados por consenso, por meio de discussão em mesa-redonda entre os membros da equipe e o moderador.

Após o levantamento dos termos descritivos, foi realizado o treinamento dos provadores durante duas semanas, às terças e quintas-feiras, às 10 e 17 horas. Nesta fase foram oferecidas cervejas modificadas, à temperatura de $10^{\circ} \mathrm{C}$, com intensidade extrema das características, de modo a propiciar aos provadores condições de discutir em mesa-redonda e para que eles se familiarizassem com todos os atributos sensoriais do produto [10]. 
A ficha de avaliação formada continha uma escala não-estruturada para cada termo descritivo levantado. A escala foi composta de uma linha de $15 \mathrm{~cm}$, com expressões quantitativas (pontos âncoras) nas extremidades esquerda e direita. Os provadores escolheram a posição que melhor refletisse sua avaliação para cada termo descritivo, e marcaram esta posição com uma marca vertical.

\section{- Seleção de provadores}

Após o levantamento dos termos descritivos e de posse de uma lista definitiva de atributos, foi realizado um teste preliminar para avaliar o desempenho dos provadores. Foram usadas, neste teste, duas amostras, com três repetições, utilizando-se os termos descritivos levantados no treinamento. Os escores foram obtidos ao medir, com o auxílio de uma régua, a distância entre o ponto-âncora da extremidade esquerda e o traço vertical realizado pelo provador.

Foi realizada a análise de variância com duas fontes de variação (repetição e amostras) para cada provador, com os resultados de cada um dos atributos. Os provadores que apresentaram probabilidade $F_{\text {amostra }} \geq 0,50$ ou probabilidade de $F_{\text {repeticăo }} \leq 0,05$ em pelo menos um atributo foram dispensados ou retreinados.

Portanto, os provadores foram selecionados de acordo com a habilidade de discriminar as amostras, a repetitibilidade e a coerência dos resultados, que foi avaliada por meio das médias de cada provador para cada atributo avaliado.

\section{- Avaliação sensorial da cerveja}

Os nove provadores selecionados e treinados avaliaram as amostras das seis marcas de cervejas, por meio dos atributos levantados. As amostras foram apresentadas, utilizando-se o delineamento de blocos incompletos balanceados proposto por COCHRAN e COX [6], com os seguintes parâmetros: $\mathrm{t}$ (número de tratamentos) $=6 ; \mathrm{k}$ (número de amostras testadas em cada sessão pelo provador) $=3 ; \mathrm{r}$ (número de vezes em que cada provador avaliou cada amostra, ou número de repetições) $=5$; e b (número de blocos ou sessões que foram realizadas por todos os provadores) $=10$.

Os resultados foram avaliados com o uso da análise de variância (ANOVA), por meio de procedimentos do programa SAS ("Statistical Analysis System"), em um modelo de dois fatores ( 6 amostras X 9 provadores), com interação dos fatores. As médias das marcas foram comparadas, aplicando-se o teste de Tukey a 5\% de probabilidade.

\subsubsection{Teste de aceitação}

Neste teste foram utilizadas as marcas 3, 4 (microcervejaria) e 5 (marca-lider de mercado), tipo Pilsen, para avaliar a aceitação do produto. As amostras foram servidas a $10^{\circ} \mathrm{C}$, em copos descartáveis de $50 \mathrm{~mL}$. O teste foi realizado em condições laboratoriais, tendo cada amostra sido analisada, individualmente, por 50 consu- midores de cerveja, através de escala hedônica de 9 pontos, sendo 1 = desgostei extremamente e 9 = gostei extremamente.

Utilizou-se o delineamento inteiramente casualizado, e os resultados foram avaliados por meio do uso da análise de variância (ANOVA). As médias foram comparadas pelo teste de Duncan, a 5\% de probabilidade.

\section{3 - RESULTADOS E DISCUSSÃO}

\section{1 - Análises físico-químicas}

Pela análise de variância, verificou-se diferença significativa $(\mathrm{P} \leq 0,05)$, entre as marcas, em relação à acidez, álcoois superiores e ésteres (Tabela 1).

TABELA 1. Médias das características físico-químicas da cerveja, expressas em $\mathrm{mg} / \mathrm{L}$

\begin{tabular}{cccc}
\hline Marca & Acidez Volátil & Álcool Superior & Ésteres \\
\hline 1 & $199,60 \mathrm{~b}$ & $170,00 \mathrm{c}$ & $105,89 \mathrm{~b}$ \\
2 & $349,23 \mathrm{a}$ & $195,83 \mathrm{bc}$ & $125,55 \mathrm{a}$ \\
3 & $140,89 \mathrm{c}$ & $225,00 \mathrm{ab}$ & $62,19 \mathrm{c}$ \\
4 & $60,790 \mathrm{f}$ & $133,33 \mathrm{~d}$ & $52,51 \mathrm{~d}$ \\
5 & $107,68 \mathrm{e}$ & $237,50 \mathrm{a}$ & $54,56 \mathrm{~d}$ \\
6 & $128,26 \mathrm{~d}$ & $220,83 \mathrm{ab}$ & $52,51 \mathrm{~d}$ \\
\hline
\end{tabular}

As médias seguidas de pelo menos uma mesma letra, na coluna, não diferem entre As medias seguidas de pelo menos uma mesma de Duncan, a $5 \%$ de probabilidade.

1 = cerveja produzida em microcervejaria, "ale" tipo Trigo.

$=$ cerveja produzida em microcervejaria, "ale" tipo Trigo.
$=$ cerveja produzida em microcervejaria, "lager" tipo Amber

= cerveja produzida em microcervejaria, "lager" tipo Pilsen

= cerveja produzida em microcervejaria, "lager" tipo Pilsen.

= cerveja lider de mercado, "lager" tipo Pilsen

= cerveja líder de mercado, "lager" tipo Pilsen

A cerveja é um produto suavemente ácido, de forma que o malte de cevada clássica possui $\mathrm{pH}$ na faixa de 4-5 e as tipo "ale" variam o pH de 3-6. Os ácidos orgânicos, que são essencialmente subprodutos excretados pelas leveduras, são os responsáveis por esta acidez. Sensorialmente, a função mais importante dos ácidos orgânicos na cerveja é aumentar a acidez do produto para um nivel agradável ao paladar humano. A concentração de ácido acético na cerveja varia de 57 a 145mg/L [9].

Para a acidez volátil das seis marcas de cerveja, expressa em mg/L de ácido acético, observou-se diferença significativa $(\mathrm{p} \leq 0,05)$ entre as marcas avaliadas, de forma que as 1,2 e 3 , provenientes de microcervejarias, foram as que apresentaram maiores médias.

Os ácidos orgânicos são importantes não somente por contribuir para o sabor e o aroma da cerveja, mas também por influenciar seu $\mathrm{pH}$, de forma que um decréscimo durante a fermentação afeta as propriedades de cerveja, como a estabilidade à turbidez não biológica, a estabilidade do sabor, a suscetibilidade e as alterações microbiológicas e a percepção do amargor, que aumenta com a elevação do pH [5].

Os álcoois superiores estão presentes na cerveja em quantidades muito baixas e contribuem para o seu aroma e sabor, dando-1he um aroma alcoólico típico de bebida fermentada. A sua sintese está associada com a assimilação de compostos nitrogenados pelas leveduras, mais precisamente pelo consumo e pela produção de ami- 
noácidos. Os álcoois superiores mais importantes encontrados na cerveja são: n-propanol, iso-butanol, 2metil-1-butanol e o 3-metil-1-butanol. Em niveis altos, os álcoois superiores afetam a qualidade da cerveja, reduzindo a qualidade da espuma e causando anormalidades sensoriais, e em casos extremos induzem dores de cabeça em pessoas suscetiveis [5, 8, 9].

Os ésteres constituem um outro grupo de compostos, formados em sua maioria durante a fermentação e que tem uma grande importância no aroma e sabor de cerveja. Os ésteres dão a este produto um aroma e sabor frutado. Quantitativa e qualitativamente, os ésteres mais importantes são: o acetato de etila e o acetato de isoamila. A presença dos ésteres no produto é desejável em concentrações apropriadas, de modo que uma falha no processo de fermentação pode resultar em niveis inaceitáveis de ésteres no produto $[9,16]$. Com relação à concentração de ésteres, das seis marcas analisadas, aquelas designadas por 1, 2 e 3 diferiram significativamente entre si e das demais marcas $(p \leq 0,05)$. Não houve diferença significativa $(p \geq 0,05)$ entre as marcas 4,5 e 6 , de menores concentrações de ésteres.

A análise de éster foi expressa em $\mathrm{mg} / \mathrm{L}$ de acetato de etila. Este éster é o que possui maior influência no aroma e sabor da cerveja, de modo que uma concentração muito alta no produto final pode distorcer o seu aroma, dando a ela um aroma forte de fruta ou uma característica forte de cerveja tipo "ale" [5, 9].

$\mathrm{Na}$ análise de álcoois superiores, observou-se que houve diferença significativa ( $\mathrm{p} \leq 0,05)$ entre as marcas. As marcas 3, 5 e 6 foram as que apresentaram maior concentrações em relação às demais.

A concentração de etanol das marcas 1 a 4 (microcervejarias) foi de $4^{\circ} \mathrm{GL}$ e das marcas 5 e 6 (marcas líderes de mercado) foi de $5^{\circ} \mathrm{GL}$. Estas concentrações são consideradas adequadas pela literatura, que evidencia o teor alcoólico ideal variando de 3 a $8 \%$ [2].

\subsection{Análise sensorial}

\subsubsection{Análise descritiva quantitativa}

\section{- Pré-seleção dos provadores}

Foram recrutados 40 candidatos a provadores, por meio de questionário. Após o recrutamento, os candidatos foram pré-selecionados, utilizando o método triangular. $\mathrm{O}$ critério para pré-selecionar os provadores foi de $50 \%$ de acertos dos seis testes triangulares apresentados, porcentagem esta igual àquela considerada adequada pela literatura [11], sugerindo-se 50 a 60\% como minimo de acerto. Dos 40 provadores recrutados, 13 foram selecionados.

\section{- Levantamento dos termos descritivos}

Depois do levantamento dos termos descritivos, foram obtidos nove termos que melhor caracterizavam as marcas de cerveja (Tabela 2).

Os 13 provadores selecionados estabeleceram a ficha final (Figura 2), por meio de discussão entre a equi- pe e o moderador. Os atributos e as expressões quantitativas de intensidade foram estabelecidos também nesta fase, e os atributos foram apresentados na ficha de acordo com a ordem em que foram percebidos pelos provadores.

TABELA 2. Lista dos termos descritivos empregados com as suas respectivas definições e referências

\begin{tabular}{|c|c|c|}
\hline Termos Descritivos & Defin ị̧ões & Referências \\
\hline Cor da Cerveja & $\begin{array}{l}\text { Intensidade variando do } \\
\text { amarelo claro ao marrom }\end{array}$ & $\begin{array}{l}\text { Padrão claro: cerveja tipo Pilsen de } \\
\text { marca comercial } \\
\text { Padrão escuro: } 100 \mathrm{~mL} \text { de cerveja tipo } \\
\text { Pilsen, adicionada de } 2 \mathrm{~mL} \text { do corante } \\
\text { caramelo }\end{array}$ \\
\hline Aroma de Levedura & $\begin{array}{l}\text { Aroma proveniente do } \\
\text { processo fermentativo }\end{array}$ & $\begin{array}{l}\text { Padrão de intensidade forte: } 2,5 \mathrm{~g} \text { de } \\
\text { fermento biológico em } 100 \mathrm{~mL} \text { de } \\
\text { cerveja tipo Pilsen } \\
\text { Padrão de intensidade fraco: } 1 \mathrm{~g} \text { de } \\
\text { fermento biológico em } 100 \mathrm{~mL} \mathrm{de} \\
\text { cerveja tipo Pilsen }\end{array}$ \\
\hline Aroma de Papelão & $\begin{array}{l}\text { Aroma resultante do } \\
\text { envelhecimento da cerveja }\end{array}$ & $\begin{array}{l}100 \mathrm{~mL} \text { de cerveja tipo Pilsen adicionada } \\
\text { de oito pedaços de papelão com } 4 \mathrm{~cm} \text { de } \\
\text { largura e } 4 \mathrm{~cm} \text { de comprimento, por } 30 \\
\text { minutos }\end{array}$ \\
\hline Aroma de Diacetil & Aroma amanteigado & $\begin{array}{l}\text { 1g de diacetil em } 100 \mathrm{~mL} \text { de cerveja tipo } \\
\text { Pilsen }\end{array}$ \\
\hline Aroma de Fruta & Aroma que lembra fruta & $\begin{array}{l}1 \mathrm{~mL} \text { de acetato de etila em } 100 \mathrm{~mL} \text { de } \\
\text { cerveja tipo Pilsen }\end{array}$ \\
\hline Sabor Oxidado & Cerveja envelhecida & $\begin{array}{l}\text { Cerveja colocada em estufa a } 40^{\circ} \mathrm{C} \text {, por } \\
24 \text { horas (baixa intensidade) }\end{array}$ \\
\hline Gosto Doce & Gosto primário & $\begin{array}{l}5 \mathrm{~g} \text { de açúcar em } 360 \mathrm{~mL} \text { de cerveja tipo } \\
\text { Pilsen }\end{array}$ \\
\hline Gosto amargo & $\begin{array}{l}\text { Gosto primário, promovido } \\
\text { pelo lúpulo }\end{array}$ & $\begin{array}{l}1 / 4 \text { de lúpulo em "pellet" em } 500 \mathrm{~mL} \text { de } \\
\text { cerveja, por } 30 \text { minutos }\end{array}$ \\
\hline Carbonatação & $\begin{array}{l}\text { Sensação gasosa no palato, } \\
\text { promovida pelo } \mathrm{CO}_{2}\end{array}$ & Cerveja descarbonatada ou regular \\
\hline
\end{tabular}

\section{- Seleção dos provadores}

O desempenho dos provadores foi verificado por meio de análise de variância, com duas fontes de variação (amostra e repetição) para cada provador, em cabines individuais e utilizando a ficha de resposta predefinida. Os provadores que apresentaram probabilidade de $\mathrm{F}_{\text {amostras }} \geq 0,50$ (baixo poder discriminativo) (Tabela 3 ) ou $\mathrm{F}_{\text {repeticão }} \leq 0,05$ (baixa repetibilidade) em pelo menos um atributo foram dispensados (Tabela 4).

A equipe que avaliou o produto foi composta pelos provadores treinados $1,2,3,4,6,7,9,10$ e 11 . Dos nove provadores, seis eram do sexo masculino e três do sexo feminino e a faixa etária variou de 20 a 50 anos.

\section{- Avaliação das amostras}

Na Tabela 5 estão os resultados das médias dos atributos sensoriais das marcas analisadas, comparadas pelo teste de Tukey, a 5\% de probabilidade.

Para o atributo cor da cerveja, todas as seis marcas apresentaram diferença significativa entre elas, tendo a marca 2 (proveniente de microcervejaria) apresentando cor mais intensa e a 5 (lider de mercado), cor menos intensa. Em comparação com as cervejas de grandes cervejarias (marcas 5 e 6), as cervejas de microcervejarias $(1,2,3$ e 4) apresentaram maior intensidade na cor.

No atributo aroma de levedura houve diferença significativa para as seis marcas analisadas, tendo a marca 2 apresentado maior intensidade deste atributo e a 5 menor intensidade. 
TABELA 3. Valores de probabilidade (p) de F

para cada provador em função das discriminações das amostras

\begin{tabular}{cccccccccc}
\hline Provador & $\begin{array}{c}\text { Cor da } \\
\text { Cerveja }\end{array}$ & $\begin{array}{c}\text { Aroma de } \\
\text { Levedura }\end{array}$ & $\begin{array}{c}\text { Aroma de } \\
\text { Papelão }\end{array}$ & $\begin{array}{c}\text { Aroma de } \\
\text { Diacetil }\end{array}$ & $\begin{array}{c}\text { Aroma de } \\
\text { Fruta }\end{array}$ & $\begin{array}{c}\text { Carbona- } \\
\text { tação }\end{array}$ & $\begin{array}{c}\text { Sabor de } \\
\text { Oxi dado }\end{array}$ & $\begin{array}{c}\text { Gosto } \\
\text { Doce }\end{array}$ & $\begin{array}{c}\text { Gosto } \\
\text { Amargo }\end{array}$ \\
\hline 1 & $\mathbf{0 , 1 8 5 6}$ & $\mathbf{0 , 2 5 3 9}$ & $\mathbf{0 , 1 1 5 8}$ & $\mathbf{0 , 4 6 5 3}$ & $\mathbf{0 , 1 2 8 2}$ & $\mathbf{0 , 0 8 2 0}$ & $\mathbf{0 , 1 1 6 8}$ & $\mathbf{0 , 3 1 0 8}$ & $\mathbf{0 , 3 2 9 0}$ \\
2 & $\mathbf{0 , 0 3 6 4}$ & $\mathbf{0 , 3 9 9 8}$ & $\mathbf{0 , 0 1 9 8}$ & $\mathbf{0 , 4 2 2 6}$ & $\mathbf{0 , 0 6 6 0}$ & $\mathbf{0 , 4 9 2 2}$ & $\mathbf{0 , 2 0 2 5}$ & $\mathbf{0 , 4 3 4 8}$ & $\mathbf{0 , 3 4 5 5}$ \\
3 & $\mathbf{0 , 1 6 6 3}$ & $\mathbf{0 , 3 2 0 3}$ & $\mathbf{0 , 3 9 7 5}$ & $\mathbf{0 , 1 8 3 5}$ & $\mathbf{0 , 0 6 2 3}$ & $\mathbf{0 , 1 2 2 4}$ & $\mathbf{0 , 0 5 7 4}$ & $\mathbf{0 , 4 1 6 6}$ & $\mathbf{0 , 2 0 7 6}$ \\
4 & $\mathbf{0 , 0 8 9 5}$ & $\mathbf{0 , 3 9 2 2}$ & $\mathbf{0 , 1 8 3 5}$ & $\mathbf{0 , 0 5 7 4}$ & $\mathbf{0 , 3 8 9 2}$ & $\mathbf{0 , 1 6 5 2}$ & $\mathbf{0 , 2 0 6 3}$ & $\mathbf{0 , 2 3 8 5}$ & $\mathbf{0 , 3 4 3 6}$ \\
5 & 0,4553 & 0,3598 & 0,7237 & 0,5277 & 0,9657 & 0,0662 & 0,7727 & 0,5253 & 0,1422 \\
6 & $\mathbf{0 , 2 9 2 4}$ & $\mathbf{0 , 0 0 2 8}$ & $\mathbf{0 , 0 9 1 8}$ & $\mathbf{0 , 1 8 3 5}$ & $\mathbf{0 , 0 7 5 6}$ & $\mathbf{0 , 3 8 1 5}$ & $\mathbf{0 , 4 2 2 6}$ & $\mathbf{0 , 0 4 0 3}$ & $\mathbf{0 , 0 4 0 3}$ \\
7 & $\mathbf{0 , 2 5 1 3}$ & $\mathbf{0 , 2 0 6 4}$ & $\mathbf{0 , 1 5 9 0}$ & $\mathbf{0 , 4 3 4 8}$ & $\mathbf{0 , 2 0 3 3}$ & $\mathbf{0 , 4 8 3 1}$ & $\mathbf{0 , 2 2 3 4}$ & $\mathbf{0 , 3 8 6 3}$ & $\mathbf{0 , 4 5 1 9}$ \\
8 & 0,8003 & 0,9474 & 0,5799 & 0,6496 & 0,8653 & 0,0908 & 0,5361 & 0,9657 \\
9 & $\mathbf{0 , 4 4 8 9}$ & $\mathbf{0 , 4 2 1 6}$ & $\mathbf{0 , 3 7 4 8}$ & $\mathbf{0 , 3 9 7 5}$ & $\mathbf{0 , 4 0 3 8}$ & $\mathbf{0 , 4 1 1 2}$ & $\mathbf{0 , 1 6 1 6}$ & $\mathbf{0 , 1 2 8 2}$ & $\mathbf{0 , 3 9 9 7}$ \\
10 & $\mathbf{0 , 2 6 6 3}$ & $\mathbf{0 , 4 1 8 6}$ & $\mathbf{0 , 0 9 2 6}$ & $\mathbf{0 , 3 7 0 3}$ & $\mathbf{0 , 0 2 9 2}$ & $\mathbf{0 , 2 8 9 1}$ & $\mathbf{0 , 3 5 3 3}$ & $\mathbf{0 , 3 4 9 7}$ & $\mathbf{0 , 1 5 1 5}$ \\
11 & $\mathbf{0 , 4 2 7 1}$ & $\mathbf{0 , 2 1 1 4}$ & $\mathbf{0 , 1 8 3 5}$ & $\mathbf{0 , 4 3 1 5}$ & $\mathbf{0 , 0 4 6 9}$ & $\mathbf{0 , 0 0 2 1}$ & $\mathbf{0 , 2 1 6 5}$ & $\mathbf{0 , 0 3 0 0}$ & $\mathbf{0 , 3 4 6 2}$ \\
12 & 0,3767 & 0,0001 & 0,8297 & 0,8111 & 0,7946 & 0,0919 & 0,2290 & 0,9538 \\
13 & 0,7874 & 0,5500 & 0,5450 & 0,5033 & 0,4821 & 0,0962 & 0,5874 & 0,7498 & 0,9205 \\
\end{tabular}

Os provadores que apresentaram $\mathrm{F}_{\text {am }}$

$\geq 0,50$ em pelo menos um atributo sensorial foram rejeitados.

TABELA 4. Valores de probabilidade (p) de $\mathrm{F}_{\mathrm{r}}$

para cada provador em função da repetibilidade dos resultados

\begin{tabular}{cccccccccc}
\hline Provador & $\begin{array}{c}\text { Cor da } \\
\text { Cerveja }\end{array}$ & $\begin{array}{c}\text { Aroma de } \\
\text { Levedu ra }\end{array}$ & $\begin{array}{c}\text { Aroma de } \\
\text { Papelão }\end{array}$ & $\begin{array}{c}\text { Aroma de } \\
\text { Diacetil }\end{array}$ & $\begin{array}{c}\text { Aroma de } \\
\text { Fruta }\end{array}$ & $\begin{array}{c}\text { Carbona- } \\
\text { tação }\end{array}$ & $\begin{array}{c}\text { Sabor de } \\
\text { Oxidado }\end{array}$ & $\begin{array}{c}\text { Gosto } \\
\text { Doce }\end{array}$ & $\begin{array}{c}\text { Gosto } \\
\text { Amargo }\end{array}$ \\
\hline 1 & $\mathbf{0 , 1 4 0 9}$ & $\mathbf{0 , 0 8 5 2}$ & $\mathbf{0 , 3 1 4 0}$ & $\mathbf{0 , 3 5 6 4}$ & $\mathbf{0 , 5 0 0 0}$ & $\mathbf{0 , 7 0 0 0}$ & $\mathbf{0 , 2 4 2 1}$ & $\mathbf{0 , 4 5 5 2}$ & $\mathbf{0 , 4 2 1 4}$ \\
2 & $\mathbf{0 , 3 7 0 0}$ & $\mathbf{0 , 5 0 0 0}$ & $\mathbf{0 , 5 0 0 0}$ & $\mathbf{0 , 5 0 0 0}$ & $\mathbf{0 , 5 1 0 2}$ & $\mathbf{0 , 9 8 6 8}$ & $\mathbf{0 , 6 4 5 0}$ & $\mathbf{0 , 5 1 0 4}$ & $\mathbf{0 , 6 7 4 3}$ \\
3 & $\mathbf{0 , 4 1 3 5}$ & $\mathbf{0 , 0 6 4 4}$ & $\mathbf{0 , 3 3 4 4}$ & $\mathbf{0 , 5 0 0 0}$ & $\mathbf{0 , 7 0 0 0}$ & $\mathbf{0 , 3 6 9 2}$ & $\mathbf{0 , 1 1 0 7}$ & $\mathbf{0 , 5 0 5 6}$ & $\mathbf{0 , 4 8 7 6}$ \\
4 & $\mathbf{0 , 4 2 6 4}$ & $\mathbf{0 , 4 3 7 8}$ & $\mathbf{0 , 0 7 1 4}$ & $\mathbf{0 , 1 1 0 7}$ & $\mathbf{0 , 5 1 9 5}$ & $\mathbf{0 , 2 8 7 2}$ & $\mathbf{0 , 5 1 5 6}$ & $\mathbf{0 , 9 3 2 3}$ & $\mathbf{0 , 6 1 1 8}$ \\
5 & 0,6412 & 0,4703 & 0,6347 & 0,3301 & 0,9494 & 0,1902 & 0,7216 & 0,0740 & 0,1328 \\
6 & $\mathbf{0 , 5 0 0 0}$ & $\mathbf{0 , 8 3 7 6}$ & $\mathbf{0 , 5 0 0 0}$ & $\mathbf{0 , 5 0 0 0}$ & $\mathbf{0 , 4 6 6 0}$ & $\mathbf{0 , 8 5 4 4}$ & $\mathbf{0 , 2 5 0 0}$ & $\mathbf{0 , 5 0 6 6}$ & $\mathbf{0 , 5 0 6 6}$ \\
7 & $\mathbf{0 , 5 4 0 2}$ & $\mathbf{0 , 0 9 7 4}$ & $\mathbf{0 , 4 8 1 8}$ & $\mathbf{0 , 5 2 1 0}$ & $\mathbf{0 , 5 1 9 5}$ & $\mathbf{0 , 7 1 4 0}$ & $\mathbf{0 , 7 4 9 5}$ & $\mathbf{0 , 4 8 9 7}$ & $\mathbf{0 , 5 1 2 3}$ \\
8 & 0,7679 & 0,8310 & 0,5000 & 0,9021 & 0,5000 & 0,1603 & 0,2568 & 0,7346 & 0,8791 \\
9 & $\mathbf{0 , 5 8 8 3}$ & $\mathbf{0 , 7 4 6 4}$ & $\mathbf{0 , 5 1 8 1}$ & $\mathbf{0 , 3 3 4 4}$ & $\mathbf{0 , 6 6 1 0}$ & $\mathbf{0 , 4 1 2 6}$ & $\mathbf{0 , 1 4 3 4}$ & $\mathbf{0 , 4 8 6 7}$ & $\mathbf{0 , 5 0 0 0}$ \\
10 & $\mathbf{0 , 5 6 2 9}$ & $\mathbf{0 , 3 2 9 1}$ & $\mathbf{0 , 5 0 0 0}$ & $\mathbf{0 , 6 1 5 0}$ & $\mathbf{0 , 7 0 6 2}$ & $\mathbf{0 , 6 0 5 7}$ & $\mathbf{0 , 5 0 0 0}$ & $\mathbf{0 , 5 4 4 1}$ & $\mathbf{0 , 1 4 8 9}$ \\
11 & $\mathbf{0 , 6 8 1 0}$ & $\mathbf{0 , 3 1 1 1}$ & $\mathbf{0 , 7 9 8 9}$ & $\mathbf{0 , 4 5 2 7}$ & $\mathbf{0 , 3 0 9 3}$ & $\mathbf{0 , 1 0 6 6}$ & $\mathbf{0 , 3 0 2 6}$ & $\mathbf{0 , 5 7 7 2}$ & $\mathbf{0 , 1 4 9 4}$ \\
12 & 0,4209 & 0,0001 & 0,0036 & 0,9476 & 0,8574 & 0,7251 & 0,0161 & 0,7565 & 0,2745 \\
13 & 0,5828 & 0,6809 & 0,7826 & 0,3786 & 0,5943 & 0,9582 & 0,2421 & 0,4906 & 0,8686 \\
\hline \hline
\end{tabular}

Os provadores que apresentaram $\mathrm{F}$

$\leq 0,05$ em pelo menos um atributo sensorial foram rejeitados

TABELA 5. Médias dos atributos sensoriais das cervejas

\begin{tabular}{|c|c|c|c|c|c|c|c|c|c|}
\hline Marca & $\begin{array}{l}\text { Cor da } \\
\text { Cerveja }\end{array}$ & $\begin{array}{l}\text { Aroma de } \\
\text { Levedura }\end{array}$ & $\begin{array}{c}\text { Aroma de } \\
\text { Papelão }\end{array}$ & $\begin{array}{c}\text { Aroma de } \\
\text { Diacetil }\end{array}$ & $\begin{array}{l}\text { Aroma de } \\
\text { Fruta }\end{array}$ & $\begin{array}{l}\text { Carbona- } \\
\text { tação }\end{array}$ & $\begin{array}{l}\text { Sabor de } \\
\text { Oxidado }\end{array}$ & $\begin{array}{l}\text { Gosto } \\
\text { Doce }\end{array}$ & $\begin{array}{c}\text { Gosto } \\
\text { Amargo }\end{array}$ \\
\hline 1 & $6,0622 b$ & $2,1556 \mathrm{~b}$ & $1,5644 \mathrm{~b}$ & $1,9067 \mathrm{a}$ & $1,9067 \mathrm{a}$ & $6,9667 \mathrm{~d}$ & $4,7400 \mathrm{a}$ & $5,0733 \mathrm{a}$ & $5,4933 \mathrm{~b}$ \\
\hline 2 & $9,9800 \mathrm{a}$ & $3,8400 \mathrm{a}$ & $3,4200 \mathrm{a}$ & $0,6644 \mathrm{~b}$ & $0,6644 \mathrm{~b}$ & $4,9867 \mathrm{e}$ & $3,2111 \mathrm{~b}$ & $3,3178 \mathrm{~b}$ & $9,1422 \mathrm{a}$ \\
\hline 3 & $4,2133 \mathrm{c}$ & $1,3400 \mathrm{c}$ & nd & nd & nd & $3,2867 \mathrm{f}$ & $\mathrm{Nd}$ & $2,0933 \mathrm{c}$ & $3,1378 \mathrm{c}$ \\
\hline 4 & $3,2511 \mathrm{~d}$ & $0,7778 \mathrm{~d}$ & nd & nd & nd & $8,1844 \mathrm{c}$ & $\mathrm{Nd}$ & $1,1978 \mathrm{~d}$ & $1,8444 \mathrm{~d}$ \\
\hline 5 & $0,3867 \mathrm{f}$ & $0,1400 \mathrm{f}$ & nd & nd & nd & $9,8889 \mathrm{~b}$ & nd & $0,2867 \mathrm{e}$ & $0,8311 \mathrm{e}$ \\
\hline 6 & $1,2933 \mathrm{e}$ & $0,3889 \mathrm{e}$ & nd & nd & nd & $10,702 \mathrm{a}$ & nd & $0,1400 \mathrm{f}$ & $0,4378 \mathrm{f}$ \\
\hline
\end{tabular}

1 = cerveja produzida em microcervejaria, "ale" tipo Trigo;

2 = cerveja produzida em microcervejaria, "lager" tipo Amber;

3 = cerveja produzida em microcervejaria, "lager" tipo Pilsen;

5 = cerve produzida en microcervejaria, "lager" tipo P

5 = cerveja lider de mercado, "lager" tipo Pilsen,

Cor = cor do produto;

Pape. = aroma de papelão;

Diac. = aroma de diacetil;

Frut. $=$ aroma de fruta;

Oxi. = sabor oxidado;

Doc. = sabor doce;
Ama. = gosto amargo;

Carb. = carbonatação

nd $=$ não-detectado 


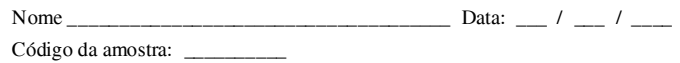

Código da amostra:

Por favor, em cada amostra, avalie os atributos listados abaixo utilizando a escal correspondente. Faça um traço vertical na posição que melhor reflete o seu julgamento. Por favor, enxágüe a boca após a avaliação de cada amostra.

APARÊNCIA

COR DA CERVEIA

\begin{tabular}{|c|c|}
\hline Fraco (amarela) & Forte (marrom) \\
\hline \multicolumn{2}{|l|}{ AROMA } \\
\hline \multicolumn{2}{|l|}{ Levedura } \\
\hline Fraco & Forte \\
\hline \multicolumn{2}{|l|}{ Papelão } \\
\hline Nenhum & Pronunciado \\
\hline \multicolumn{2}{|l|}{ Diacetil } \\
\hline Nenhum & Muito \\
\hline Fruta & \\
\hline Nenhum & Forte \\
\hline \multicolumn{2}{|l|}{ CONSISTÊNCIA } \\
\hline \multicolumn{2}{|l|}{ Carbonatação } \\
\hline Fraca & Forte \\
\hline \multicolumn{2}{|l|}{ SABOR } \\
\hline \multicolumn{2}{|l|}{ Oxidado } \\
\hline Nenhum & Forte \\
\hline \multicolumn{2}{|l|}{ GOSTO } \\
\hline Doce & - \\
\hline Nenhum & Forte \\
\hline Amargo & \\
\hline Fraco & -1 \\
\hline Fraco & Forte \\
\hline
\end{tabular}

FIGURA 2. Ficha de resposta para avaliar as amostras de cerveja pelo método de análise descritiva quantitativa.

No atributo aroma do papelão, houve diferença significativa entre as marcas 1 e 2 , de modo que a marca 2 foi a que apresentou maior intensidade deste aroma; este atributo estava ausente nas marcas 3, 4, 5 e 6. O mesmo ocorreu para os atributos aroma de diacetil, aroma de fruta e sabor oxidado, pois somente as marcas 1 e 2 apresentaram estes atributos. Em relação ao aroma de diacetil, a marca 1 foi a que apresentou maior intensidade do atributo. A marca 1 também apresentou maior intensidade dos atributos aroma de fruta e sabor oxidado.

Em relação ao atributo carbonatação, observou-se diferença significativa entre as seis marcas de cerveja, no entanto, a 6 foi a que apresentou maior intensidade deste atributo e a 3 menor intensidade.

Para o atributo gosto doce, houve diferença significativa entre as seis marcas de cerveja, tendo a marca 1 apresentado maior intensidade deste atributo e a 6 menor intensidade.

No atributo gosto amargo, as seis marcas apresentaram diferença significativa, porém a 2 apresentou maior intensidade deste atributo e a 6 menor intensidade. As amostras 1 e 2 apresentaram elevadas con- centrações de acidez (Tabela 1), sendo identificadas pelos provadores com um elevado escore de amargor, o que contraria o esperado, pois, de acordo com BUSHELL [5], quanto mais baixo o $\mathrm{pH}$ menor é a percepção sensorial do gosto amargo da cerveja. Outros compostos, além daqueles provenientes do lúpulo, podem ter auxiliado para que o gosto amargo tenha sido acentuado nessas duas marcas de cerveja.

O perfil sensorial das amostras das seis marcas de cerveja está representado na Figura 3, em representação axial. Essa figura evidencia diferenças entre as amostras de cerveja em relação aos termos descritivos analisados.

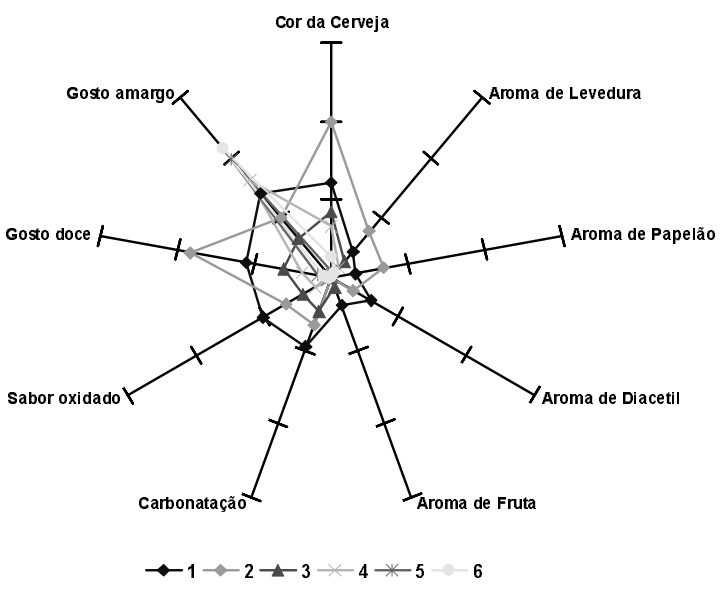

1 = cerveja produzida em microcervejaria, "ale" tipo Trigo.

$2=$ cerveja produzida em microcervejaria, "lager" tipo Amber
$3=$ cerveja produzida em microcervejaria, "lager" tipo Pilsen 4 = cerveja produzida em microcervejaria, "lager" tipo Pilsen. 5 = cerveja lider de mercado, "lager" tipo Pilsen. $6=$ cerveja lider de mercado; "lager" tipo Pilsen.

FIGURA 3. Perfil sensorial das seis marcas de cerveja.

\subsubsection{Teste de aceitação}

Apenas as marcas 3, 4 e 5 foram comparadas com relação à aceitação por representarem o mesmo tipo de cerveja (Pilsen), grupo diferenciado dos demais. Não houve diferença significativa ( $p \geq 0,05)$, em relação à aceitação, entre as amostras. Todas as amostras situaram-se entre os termos hedônicos "gostei muito" e "gostei ligeiramente". (Tabela 6).

TABELA 6. Comparação das médias das marcas de cerveja obtidas no teste de aceitação

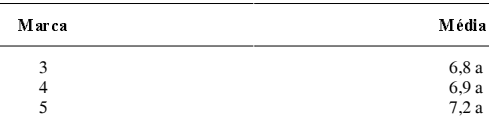

As médias seguidas de pelo menos uma mesma letra não diferem entre si pelo teste de Duncan $(p>0,05)$.

Marcas 3 e 4 = cerveja tipo Pilsen produzida em microcervejaria; e marca $5=$ cerveja tipo Pilsen líder de mercado.

Apesar de não haver diferença significativa em relação à aceitação entre as cervejas tipo Pilsen produzidas pelos dois segmentos de mercado, observou-se diferen- 
ça significativa em relação aos atributos sensoriais detectados pela equipe sensorial treinada. Desta forma, as cervejas tipo Pilsen produzidas pelas microcervejarias, de acordo com a avaliação dos consumidores, se adequam ao padrão das cervejas produzidas pelas grandes marcas. No teste de aceitação observa-se que os consumidores não possuem conhecimento, por exemplo, de sabores "velho" ou "oxidado", que são detectados por uma equipe sensorial treinada (AXCELL \& TORLINE [3]). Uma cerveja pode estar mais ou menos amarga, com mais ou menos aroma de levedura em relação a uma outra cerveja, e, no entanto, os consumidores podem não considerá-los como atributos negativos do produto.

\section{4 - CONCLUSÕES}

As análises fisico-químicas mostraram que as amostras 1 e 2 apresentaram elevadas concentrações de acidez e foram caracterizadas pelos provadores com um elevado escore de amargor. Observou-se que os demais atributos sensoriais também se apresentaram em maior intensidade nestas marcas, provenientes de microcervejarias, caracterizando-se pela cor, aroma de levedura, aroma de papelão, aroma de fruta, aroma de diacetil, gosto doce e sabor oxidado mais intensos.

As amostras que apresentaram maior concentração de acetato de etila apresentaram aroma de fruta perceptível. Não foi detectado, sensorialmente, aroma de fruta nas marcas 3, 4, 5 e 6, que são cervejas tipo Pilsen, nas quais as marcas 3 e 4 são provenientes de microcervejarias.

Não foi observado, nas amostras, aroma de solvente, o que indica que a concentração de álcoois superiores, que poderia estar associado a este atributo, está abaixo do limiar de detecção em todas as amostras.

Ao comparar as duas cervejas tipo Pilsen produzidas em microcervejaria com as duas cervejas tipo Pilsen lideres de mercado, pôde-se observar que as cervejas de microcervejaria possuem maior intensidade dos atributos sensoriais, diferenciando-se na cor, no aroma de levedura, no gosto doce e no sabor amargo. No entanto, essas diferenças na intensidade dos atributos sensoriais não resultaram em diferença significativa $(p \geq 0,05)$ para a aceitação do produto, contrariando o esperado, pois as microcervejarias objetivam uma cerveja mais artesanal e de maior atração para o consumidor.

$O$ atributo sensorial carbonatação apresentou-se com maior intensidade nas marcas 5 e 6 (lideres de mercado) e pode demonstrar uma diferenciação tecnológica entre os dois segmentos de mercado.

\section{5 - REFERÊNCIAS}

[1] A CERVEJA NO BRASIL. http//www.montana.com.br. Novembro, 1999.

[2] AQUARONE, E., LIMA, U.A., BORZANI, W. Biotecnologia: alimentos e bebidas produzidas por fermentação. São Paulo: Edgard Blücher. v.5, 1983. 243p.

[3] AXCELL, B., TORLINE, P. Some alternative views on beer flavour. Technical Quarterly, v.35, n.2, p.91-94, 1998.

[4] BRASIL. Ministério da Agricultura. Secretaria Nacional de Defesa Agropecuária. Laboratório Nacional de Referência Vegetal (LANARV). Metodologia de Análises de Bebidas e Vinagres. [S. L.]: [19-]. Paginação irregular.

[5] BUSHELL, M.E. Progress in industrial microbiology. Oxford: Elsevier, 1984. 198p.

[6] COCHRAN, W.G., COX, G.M. Diseños experimentales. México: Trillas, 1981. 661p.

[7] FUKASAWA, Y., SHINODA,T., NISHIKAWA, A. and NAKASE, T. Synonymy of Saccharomyces cerevisiae Hansen 1883 and Saccharomyces uvarum Beijerinck 1898: significance of cell wall antigens in yeast classification. Intern. J. System. Bacteriol., v.1, n.30, p.196-205, 1980.

[8] GARCIA, A.I., GARCIA, L.A., DÍAZ, M. Fusel alcohols in beer fermentation process. Process Biochemistry, n.29, p.303-309, 1994.

[9] HARDWICK, W.A. Handbook of brewing. New York: Dekker, 1995. 713p.

[10] MECREDY, J.M., SONNEMANN, J.C., LEHMANN, S.J. Sensory profiling of beer by a modified QDA method. Food Technology, v.28, n.11, p.36-41, 1974.

[11] MEILGARD, M., CIVILLE, V. and CARR, B.T. Sensory evaluation techniques. CRC Press Inc, Bocca Ratton, Flórida, 1988, 279 p.

[12] NEVES, A.L.R.A. Viabilidade técnico-econômica e análise de risco da implantação de microcervejarias no Brasil. Viçosa-MG: UFV, 1996. 79p. Dissertação (Mestrado em Ciência e Tecnologia de Alimentos) - Universidade Federal de Viçosa.

[13] PALAMAND, R. Training ourselves in flavor perception and tasting. In: Evaluating beer. Brewers Publications, Boulder, Colorado, p.115-131, 1993.

[14] ROSA, A. Loura gelada e sofisticada. Jornal do Brasil, Rio de Janeiro, 24 de maio, 1998. Caderno Seu Bolso, p.5.

[15] STAUFFER, J.E. Microbrewing: a lesson in agile manufacturing. Cereal Foods World, v.43, n.9, p.770$771,1997$.

[16] STEWART, G., LYNESS, A., YOUNIS, O. The control of ester synthesis during wort fermentation. Technical Quarterly, v.36, n.1, p.61-66, 1999.

[17] TIPOS DE CERVEJAS. http//www.montana.com.br. Novembro, 1999.

[18] VARNAM, A.H., SUTHERLAND, J.P. Bebidas. Espanha: Acribia, 1997. 487p. 